\title{
Noise Exposure Levels in Basic School Environments in a City in Ghana
}

\author{
Lois N. K. Quartey¹, Samuel Amos-Abanyie², Samuel 0. Afram² \\ ${ }^{1}$ Project Coordinator, Building Early Accra Project/Sociarchi, Accra, Ghana \\ ${ }^{2}$ Department of Architecture, Kwame Nkrumah University of science and Technology, Kumasi, Ghana \\ Email: s.a.abanyie@gmail.com
}

How to cite this paper: Quartey, L.N.K., Amos-Abanyie, S. and Afram, S.O. (2021) Noise Exposure Levels in Basic School Environments in a City in Ghana. Open Journal of Civil Engineering, 11, 81-95. https://doi.org/10.4236/ojce.2021.111006

Received: September 11, 2020

Accepted: March 9, 2021

Published: March 12, 2021

Copyright (c) 2021 by author(s) and Scientific Research Publishing Inc. This work is licensed under the Creative Commons Attribution International License (CC BY 4.0).

http://creativecommons.org/licenses/by/4.0/

(c) (i) Open Access

\begin{abstract}
Basic schools that are located in heavily populated residential and commercial areas in Ghana are exposed to environmental noise that can have detrimental effects on the academic attainments of children. Limited studies have been conducted on noise level in basic schools to date in Ghana. The objective of the study was to assess noise levels in and around learning spaces in basic schools in Ghana with a focus on Kumasi. A survey employing the use of interviews and an empirical monitoring of noise levels in and around learning spaces in four selected basic schools were adopted. The study revealed that mean outdoor and indoor noise levels exceed the World Health Organisation permissible limits by 30 - 40 percent and $90-107$ percent respectively for schools in the commercial zones and schools that are located near highways. The school that is sited in an educational environment with a setback from the highway attained mean noise levels ranging from 1.2 percent below to 3.7 percent above the permissible limits for outdoor and between $64-105$ percent for indoor. The outcome of the study is expected to engender the design of environmental noise resilient buildings to facilitate teaching and learning in basic schools in Ghana.
\end{abstract}

\section{Keywords}

Environmental Noise, Sound Level, Basic Schools, Central Business District, Kumasi

\section{Introduction}

In the modern world, schools provide children with a key part of their childhood experience and form one of their principal social activities and setting [1]. According to [2], a suitable school environment encompasses social, physical and biological factors that fosters appropriate behaviour and facilitates learning. 
Moreover, the Ottawa Charter for Health Promotion states that "health is created and lived by people within the settings of their everyday life; where they learn, work, play and live" [3]. Furthermore, as learning in classrooms is mainly facilitated through verbal and auditory communication between teachers and students [4] [5], good quality school buildings are required.

According to the World Health Organization (WHO), environmental challenges vary considerably among schools around the world, across countries and within communities [6]. In developing countries, majority of educational institutions are located close to commercial zones and in heavily populated residential communities. [7] attributes the siting of schools near busy and noisy environments in developing countries to either limited places to build schools or rapid development in the vicinity of existing schools. The problem is compounded by unbalanced urban development and increasing mobility and road traffic [8]. In Ghana, the increased rate of noise pollution in community school environments could present a real public health challenge. A study by [9] revealed that a high level of noise pollution prevails in parts of cities in Ghana throughout the day with city dwellers being exposed to excessive noise higher than the WHO permissible limits by $34 \%-40 \%$ in residential zones and $14 \%-18 \%$ in commercial zones.

Schools in the developed world are fully equipped with sound insulation techniques and modern technology to minimize intrusion of environmental noise from the surroundings [7]. In Ghana, as in other developing countries, there is predominant use of sandcrete blocks which is a light weight envelope material with low sound insulation properties for school buildings. In spite of extensive research on effects of noise on children's learning and performance at school having been conducted in the past 30 years [1], limited studies have been conducted on noise levels in basic schools to date in Ghana. Moreover, acts and regulations guiding noise control practices in Ghana are limited and not strictly adhered to.

The above context raises issues such as what are the environmental noise levels in and around community schools; what are the perceptions of environmental noise amongst pupils and staff of community schools; and what are the possible effects of long exposure to environmental noise on the behaviour and performance of pupils? This study is aimed at assessing noise levels in selected basic school classrooms in the Greater Kumasi Metropolis. The study is expected to engender the design of environmental noise resilient buildings for basic schools in Ghana to enhance the character of the learning environment, facilitate teaching and learning, and improve pupils' performance.

\section{Effects of Noise on Children at School}

Efforts at improving the quality of education and teaching in schools in many countries, as in the case of Ghana, have focused on physical characteristics of school buildings, classroom sizes, quality of teachers, syllabi, and textbooks [10] 
[11]. However, in as much as these play important roles in the quality of education, the suitability of the school climate also requires due consideration. The WHO defines a health-promoting school as "one that constantly strengthens its capacity as a healthy setting for living, learning and working" [12].

[13] identified road traffic as the predominant external noise source, particularly in urban areas. In Ghana, children in classrooms at schools are exposed to external noise from a wide variety of sources emanating from transport system, industrial activities, and noise of people outside the school transmitted through the building envelope. The adoption of lightweight construction with no insulation in response to the climate makes the acoustic conditions in schools inappropriate thus achieving indoor noise levels that are greater than the recommended levels. [11] asserts that, indoor noise levels could be worsened by inappropriate material of interior surfaces with regard to the acoustic resonance and its reflection. An additional source of noise which cause significant disturbance to teaching is the noise of rain falling on the light weight roofs. There is however very limited exposure to noise from aircraft and railway due to their inadequate development as a means of transport in Ghana.

Internally, noise may be generated from teaching equipment such as computers and projectors, and building services equipment in the classroom [14]. Several studies, including [1] and [15] established that, even when pupils are silent in a classroom, their presence significantly increases the noise level above that of the unoccupied condition.

Generally, harmful noise has been associated with extremely loud sounds that can cause immediate hearing loss. However, [16] asserts that chronic noise exposure even at moderate levels can result in irreversible damage. Moreover, [17] and [18] describe noise at school, in and around the classroom, as insidious and the associated psychological and physiological outcomes are often overlooked by parents and educators. More commonly recognized student concerns, such as attention deficit disorder or behaviour problems, may be blamed. According to studies by [19] and [20], students' learning experiences generally contribute to the development of their interest in specific learning domains and talents. The above implies that, if the domains are influenced by noise, then the student cannot fully concentrate, and the development and improvement of students might be hindered.

Because most classroom instructions are conveyed through spoken language, it makes noise one of the main factors having a negative effect on school climate and learning environment [4]. Noise pollution around educational institutions can pose a number of multi-problems to the teaching and learning process. Amongst them are discomfort among teachers and students, irritability, lack of concentration, fatigue, headache, speech interference, masking [11] [13] [21] and eventual decline of student's academic performance. In instances of speech interference with teachers having to raise their voice could result in fatigue, thus reducing effective teaching periods. Early-age exposure to noise could also pose many 
long-term health implications such as age-specific hearing, inadequate learning coping strategies, and alterations in biological stress regulatory responses of which limited knowledge is available [22].

Effective education and teaching require keeping classroom noise levels within specific limits. There are several national and international guidelines related to the acoustics of classrooms that take the form of recommended values for reverberation time, background noise levels in teaching spaces, and sound insulation requirements for school buildings. The WHO guidelines recommend background sound pressure level of $35 \mathrm{~dB}$ LAeq in classrooms during teaching sessions in order to be able to hear and understand spoken messages. For outdoor environments in schools, sound pressure level of $55 \mathrm{~dB}$ LAeq from external sources is recommended [23].

[14] in a survey of primary school classrooms found that the mean noise level when pupils were silent was $56 \mathrm{~dB}$ in acoustically untreated classrooms, and drops to $46.5 \mathrm{~dB}$ in treated rooms. Most school buildings in Ghana have no acoustic treatment and as such children's performance in word intelligibility tests and improved letter, number and word recognition could be hindered. [1] found that measured sound levels in classrooms ranged from $56 \mathrm{~dB}$ (silent activity) to $77 \mathrm{~dB}$ when the pupils were engaged in activities such as group work and movement around the classroom. This suggest that the ambient noise level in an occupied primary school classroom was closely related to the pupil activity.

\section{Study Context}

The Greater Kumasi Metropolis in the Ashanti Region of Ghana has a strategic central location with a significant transit role in absorbing the movement of people from the south to the north of the country and vice versa [24]. Rapid population growth, uncontrolled physical development and commercialization are the major factors, which results in environmental pollution. Within the commercial zones, vehicular noise and loudspeakers that are mounted for broadcast, add to the cacophony of noise levels which generate excessive noise beyond the acceptable levels set by the EPA [25].

Four public basic schools in The Greater Kumasi Metropolis were purposefully selected (Figure 1) to cover exposure to a wide range of noise sources experienced in schools in Ghana, by virtue of proximity to busy roads or highway traffic, market area or commercial activities. One of the schools is located in a well zoned educational environment of a university campus. The schools are: 1) KO Methodist Basic School, Kejetia; 2) New Amakom Metropolitan Authority Basic School, Amakom (Figure 2); 3) Weweso Metropolitan Authority School, Kentikrono; and 4) Kwame Nkrumah University of Science and Technology (KNUST) Basic School.

The KO Methodist Cluster of Schools is bounded by commercial activities in a chain of shops and offices (Figure 3). The predominant sources of noise are vehicles, trading activities/hawking, and vans with public address systems used to 
merchandise assorted products. The New Amakom Metropolitan Authority School is located off the Accra-Kumasi Highway which is towards the north of the school (Figure 4). The Weweso Metropolitan Authority School is located along the Accra-Kumasi Highway in a residential setting with commercial activities dotted around the school. The KNUST Basic School is located in a well zoned educational environment of a serene university campus.

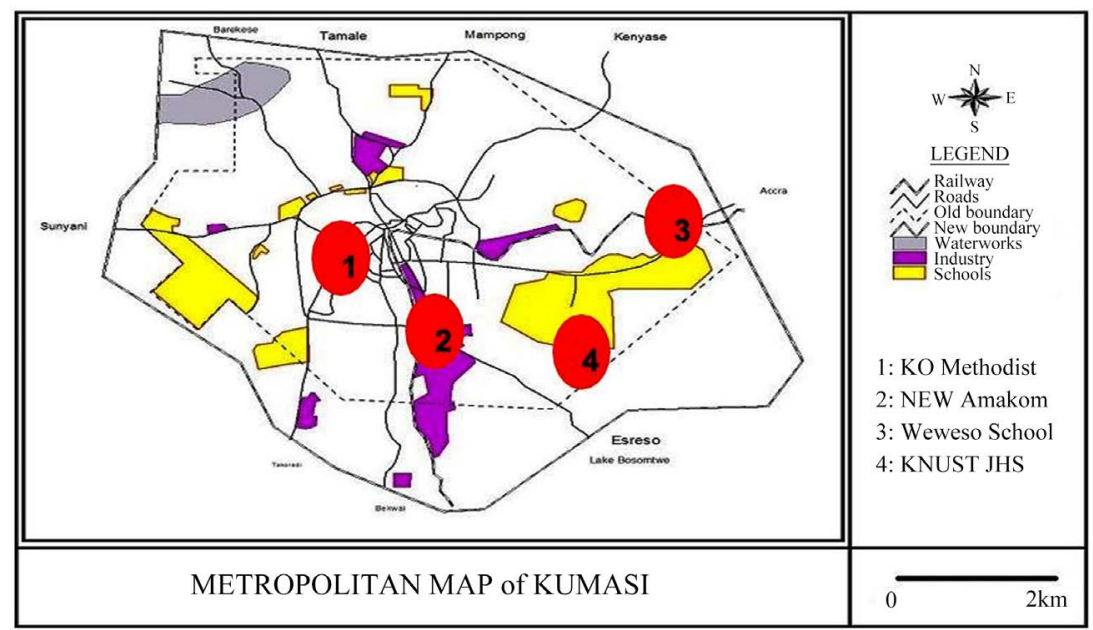

Figure 1. Location of study schools within the context of the Kumasi [26].

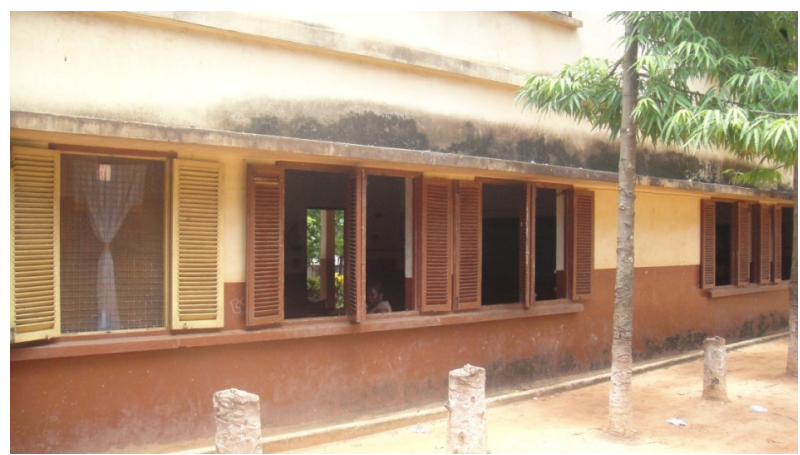

Figure 2. External view of a classroom block of the New Amakom Basic School.

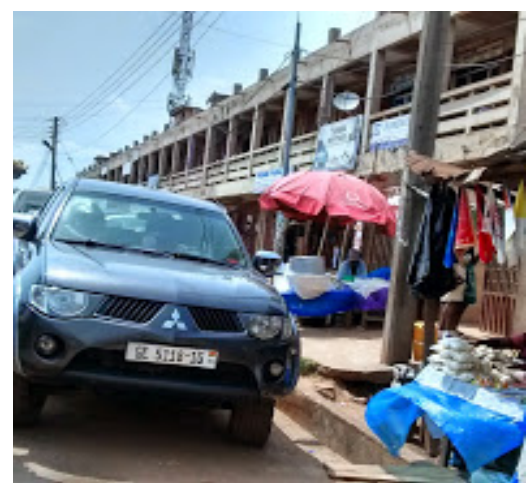

Figure 3. Commercial activities around the KO Methodist School. 


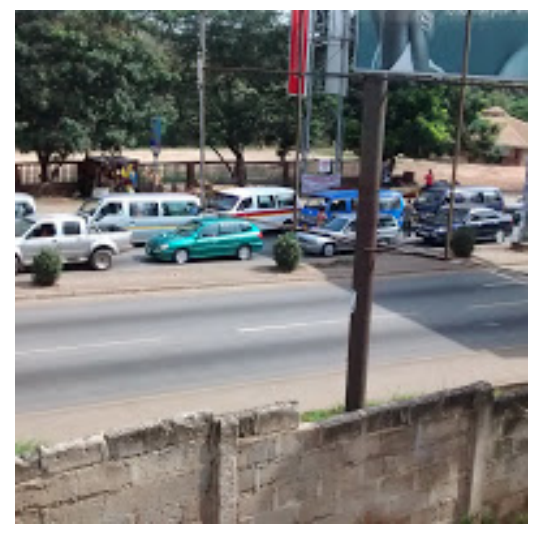

Figure 4. Vehicular traffic in the vicinity of the New Amakom M/A School.

\section{Methodology}

Two key methods were employed in the study: a survey, comprising interviews and observations, and empirical monitoring of noise levels. For the survey, two sets of self-completion questionnaires were designed, one used to elicit responses from pupils and the other from teachers. Both questionnaires elicited background information of respondents and the extent of knowledge on the sources as well as perceptions of noise and possible acoustical discomforts and physiological constraints in their schools. Twenty-three (23) pupils and six (6) teachers were randomly selected from each of the four (4) selected schools, making a total ninety-two (92) pupils and twenty-four (24) teachers. Among the pupils thirty-eight (38) were males and fifty-four (54) females, of which forty-three (43) were in Junior High School (JHS) and thirty-nine (39) in the primary. The pupils aged between 9 - 16 years. The age group 12 - 14 had the greatest respondents. It however, gives a fair description of perceptions since the respondents were randomly selected. The teachers comprised nine (9) male and fifteen (15) females, out of which seven (7) teachers were new and have been posted to their schools in the last three years. Personal observations provided first hand knowledge of the location as well as the layout of the schools, the envelope materials and the type of openings (doors and windows) used in construction and the general forms of architecture present. Measured drawings were made with the aid of a tape measure. A sketchbook was used to record data manually by drawing the conceptual diagram of classroom blocks.

Empirical monitoring was conducted to be able to obtain the prevailing the noise levels in and around the classrooms of the selected basic schools. Four (4) classrooms were chosen randomly from each school for empirical monitoring allowing for a total of 16 classrooms. A well calibrated PCE222 Digital Sound Level Meter, having an accuracy of $\pm 1.5 \mathrm{~dB}$ and a measuring range from 30 to $130 \mathrm{dBA}$ was used to monitor indoor and outdoor noise levels, as done by [27] and [9]. The recordings followed the standard of ambient environmental noise and were conducted with the sound level meter switched to slow response posi- 
tion. Noise levels were monitored over a three-week period, for both indoor and outdoor locations to enable a comparison of internal and external noise levels. Typical noise monitoring locations are presented in Figure 5.

All measurements were conducted in occupied classrooms during lessons and class activities. Continuous data was collected at an interval of 2 minutes for all the time periods in the selected spaces. Internal noise monitoring was undertaken for thirty minutes and the external monitoring was undertaken for the next thirty minutes within an hour. All noise monitoring were made with the sound level meter placed at a height of $1.5 \mathrm{~m}$ above ground level on an iron stand to avoid reflection of sound waves off the ground and floor surface.

Using Microsoft Excel, average level of every hour monitored was computed and grouped into morning (8:00-11:00 hr), afternoon 11:00-14:00 hr) and evening (14:00-16:00 hr) using school hours timing. 7:00am-10:00am for morning, $10: 00 \mathrm{am}-1: 00 \mathrm{pm}$ for the afternoon and 1:00pm and beyond were the evening hours. Mean noise levels for outdoor and indoor over the time periods were compared to the respective permissible limits prescribed by the [23]. SPSS version 24 was used for analysis of the survey data.

\section{Results and Discussions}

Computed mean sound levels in decibels of the maximum and minimum sound levels data monitored outdoors and in selected classrooms over the study period and the perceptions of pupils and teachers through the responses to the questionnaires are discussed in the following sections.

\subsection{Environmental Noise Levels in Schools}

The monitored data of outdoor noise levels in the selected schools ranged between $54-79 \mathrm{~dB}$, while the indoor average values ranged between $57-73 \mathrm{~dB}$ (Table 1).

The KO Methodist Cluster of Schools which is located in a commercial zone had the highest noise levels for both outdoor and indoor. Sound level at outdoors have a mean of $78.6 \mathrm{~dB}$ for morning, $76.0 \mathrm{~dB}$ for afternoon and $77.7 \mathrm{~dB}$ for evening. The maximum outdoor sound level when classes are in session was 86.7

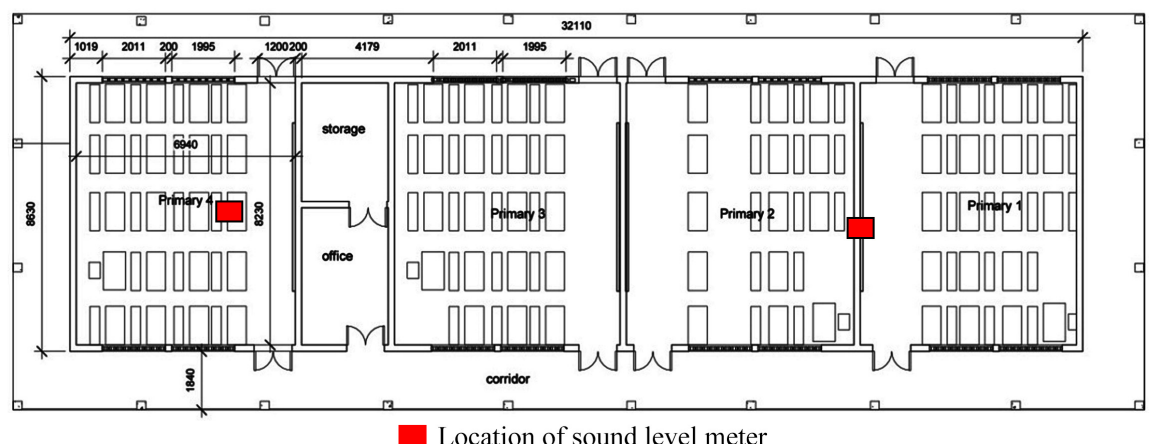

Figure 5. Schematic floor plan of classroom block at Weweso M/A Basic School. 
Table 1. Mean sound levels in decibel for Schools at different time periods. The values indicated in the parenthesis are the percent increase of sound level than the permissible limits.

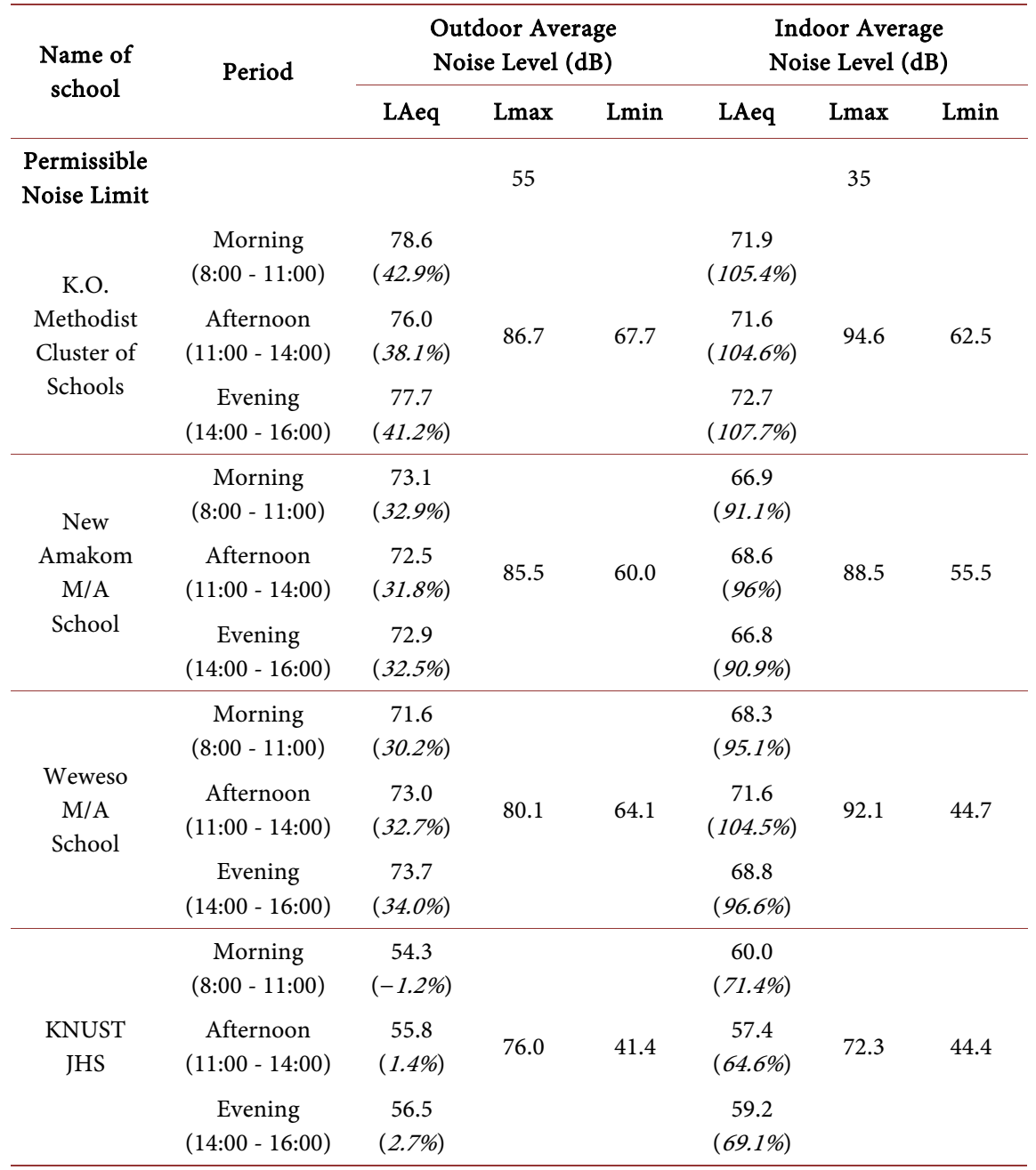

$\mathrm{dB}$ and the minimum was $67.7 \mathrm{~dB}$. Indoor mean sound level for the $\mathrm{KO} \mathrm{Me}$ thodist Cluster of Schools was $71.9 \mathrm{~dB}$ for morning, $71.6 \mathrm{~dB}$ for afternoon and $72.7 \mathrm{~dB}$ for evening. An empty class had a mean sound level of $64.3 \mathrm{~dB}$. The reason for the higher noise levels were due to greater number of noise sources primarily from vehicles and commercial activities within the vicinity of the school. Pupils in this school can suffer from a detrimental effect on their reading abilities when their exposure to noise of the observed mean levels become chronic (Evans and Lepore (1993) in [2].

The external noise levels at New Amakom Metropolitan Authority School had a mean of $73.1 \mathrm{~dB}$ for morning, $72.5 \mathrm{~dB}$ for afternoon and $72.9 \mathrm{~dB}$ for evening of school hours. In spite of the relatively lower noise levels, the mean sound levels exceed the permissible limits prescribed for school environments by the World Health Organization [23]. The lowest external noise level recorded was $67.2 \mathrm{~dB}$ and the highest was $76.2 \mathrm{~dB}$ which were within the evening time period. The in- 
ternal mean values were however lower with consideration to the ongoing activities as at the time of measurement. The morning attained a mean of $66.9 \mathrm{~dB}$, afternoon had $68.6 \mathrm{~dB}$ and evening $66.8 \mathrm{~dB}$. The internal mean level is approximately twice as high as permissible limit of $35 \mathrm{~dB}$. The minimum mean level was $60.4 \mathrm{~dB}$ and the maximum was $72.1 \mathrm{~dB}$. The above implies that the envelope of the school building and its environment absorb some of the environmental noise but not well enough to prevent it from reaching the classrooms. Speech interference, disturbance of information comprehension and message communication as part of the process of education amongst pupils in this school can be affected [5]. Moreover, pupils' learning through transfer of information from the teacher and their social interaction, as they cannot hear and understand their peers in the classroom, will be hindered [2]. Pupils' in this school can have their long-term recall also being affected by exposure to noise from environmental noise sources such as transportation [28].

The New Amakom Metropolitan Authority Basic School has a lot of trees that provide a very serene environment. [29] established that trees provide a barrier to noise and are able to achieve reductions of between 4 and $6 \mathrm{~dB}$ for foliage width of about 30 metres. However, the close proximity to the busy highway exposes the schools to high noise level above the permissible limit making the trees ineffective as noise barrier.

The mean noise level at Weweso Metropolitan Authority School gave clear indication of a noisy environment. A mean outdoor noise level of $71.6 \mathrm{~dB}$ was attained for morning, $73.0 \mathrm{~dB}$ for afternoon and $73.7 \mathrm{~dB}$ for evening over the period of study. The lowest outdoor mean noise level was $70.8 \mathrm{~dB}$ which has a difference of $4.3 \mathrm{~dB}$ from the highest outdoor mean level. The mean indoor level was $68.3 \mathrm{~dB}$ for morning, $71.6 \mathrm{~dB}$ for afternoon and $68.8 \mathrm{~dB}$ for evening. This is because the external noise levels in Weweso are directly influenced by vehicular activity on the Accra-Kumasi Highway. Pupils of this school may have their attention disrupted, develop aggressiveness, suffer from reduced physical and mental performance, and experience irritation and discomfort [30] [31]. Such high level of noise identified in the school can also negatively disturb the pupils' motivation and ability to concentrate during class, coupled with reduced memory and their ability to carry out a complex task [1].

The mean noise levels for the KNUST JHS were found to have the lowest averages, even though they exceed the permissible limits by WHO (1999). The KNUST JHS has higher mean indoor noise level than the mean outdoor, as presented in Table 1. The morning period had a mean noise level of $54.3 \mathrm{~dB}, 55.8$ $\mathrm{dB}$ for afternoon and $56.5 \mathrm{~dB}$ for evening. The mean indoor noise levels are 60.0 $\mathrm{dB}, 57.4 \mathrm{~dB}$ and $59.2 \mathrm{~dB}$ for morning, afternoon and evening respectively. The reason for the relatively lower mean outdoor monitored noise levels could be attributed to the school's location on a university campus with restricted vehicular activity, and the provision of clear and adequate buffer zones. The higher mean indoor noise levels could be explained by the fact that the dominant source of 
noise in a primary school classroom is the noise generated by the pupils themselves [1]. The observed higher indoor mean noise level than that of the outdoor could be explained by the fact that presence of pupils in a classroom space can significantly increase the noise level above that of the unoccupied condition [1]. Pupils in this school can perform better since their environment has a relatively quiet condition as compared to other schools [32].

A special study carried out in the courtyard of the classroom blocks at the KNUST JHS revealed that it had noise levels that were much lower compared to other areas of the school. Noise level in the inner courtyard was as low as $43.8 \mathrm{~dB}$.

\subsection{Perceptions of Staff and Pupils of Environmental Noise Levels in Schools}

The perceptions of the staff and pupils from the interviews are outlined and discussed in this section. Perceptions of students and staff confirm inferences drawn from the monitored sound level. On the level of exposure of the school to noise, all the staff interviewed and eighty-two percent (82\%) of the pupils were of the view that the schools are exposed to noise and not conducive for proper child development. Out of the number, 54\% of pupils indicated that the noise levels were high between the hours of $10 \mathrm{am}-12 \mathrm{pm}$ followed by the $29.2 \%$ claiming it is high between the hours of 8am-10am.

Questions regarding the sources of noise to the school environment, the main sources were from vehicles, motorbikes and music vans (traffic noise). The other sources include music shops, vehicle repair, trading and hawking. Measures adopted by the staff in controlling environmental noise include the closing of doors and windows. This can affect day lighting levels and natural ventilation use in the classrooms [33]. Moreover, the form of fenestration (jalousie windows and louver blades) allowed much of outdoor noise into the learning spaces.

On the adverse effects of noise, a greater proportion of the pupils forming $37.7 \%$ claimed the high noise level disrupts teaching and learning process. While $35.8 \%$ of the respondents claimed it created some difficulty in paying attention, with $17 \%$ claiming difficulty in discussions in class, and $9.4 \%$ attributed some of the health problems experienced by some students to effects of noise. The high environmental noises level could affect their academic performance [1].

In response to pupils' opinions on how satisfied they found the learning environment, $47.9 \%$ of pupils in schools in the commercial zone and close to the highway were not satisfied with the location of the school and $44 \%$ preferred the option of a different school. Other pupils were of the opinion that relocating the school was a better option. The negative perceptions of the pupils can affect their satisfaction of the school environment, both indoors or outdoors, and student satisfaction promotes more active behaviour [2].

\section{Implications of the Findings}

The results of the study show that noise levels vary among schools of different 
environments and monitoring time periods within the day, and could be attributed to the activities at given locations. The different environments in which schools were monitored are: highway/residential environment, commercial environment, and educational environment. The peak noise levels were observed in schools sited in a commercial environment followed by that in the highway/residential environment, in the morning (08.00-11.00 hrs) and afternoon (11.00-14.00 hrs) periods. The school in the commercial environment had the highest $\mathrm{L}_{\text {Aeq }}$ during the morning $(08.00-11.00 \mathrm{hrs})$, while the school in the educational environment recorded the lowest. The results also show that peak outdoor noise levels in the schools exceeded the recommended level of $55 \mathrm{dBA}$ by between $30 \%$ to $41 \%$.

The levels of noise in the studied schools compare with observed levels in earlier studies on noise levels in parts of cities in Ghana where significant values were established [9] [36] [34] [35]. [9] [35] [36] attributed the high levels of noise in the cities to increased use of vehicles. On densely utilized roads, the equivalent sound pressure levels can reach up to $75-80 \mathrm{~dB}(\mathrm{~A})$ [9].

Among the schools studied, indoor average noise levels were also above the recommended level of $35 \mathrm{~dB}$ by between $69 \%$ and $108 \%$. A striking observation is that, the school studied in the educational environment which had lower outdoor noise level than the recommended level in the morning period attained an indoor level of $60.0 \mathrm{db}$ that exceeds the recommended indoor level by $71.6 \%$. This compares with a range observed in occupied levels in a full range of classrooms from kindergarten to university which varied from 42 to $94 \mathrm{~dB}$, in a review by [37]. The measured relatively high level of noise in the schools monitored could be attributed to the absence of acoustic treatments in the classrooms. In a study involving 140 primary school classrooms by [38], the dominant source of noise inside a primary school classroom was the noise generated by the pupils, teaching equipment, building services in the classroom, and noise transmitted through the building elements.

In a study by [39], old buildings that had bigger classrooms than the modern buildings were associated with a corresponding increase in the amount of relative surface area, thus contributing to reverberant sound level being higher in the old schools. The lower mean indoor levels of noise in the school within the educational environment could also be attributed to its having relatively smaller classrooms sizes associated with recently developed school buildings. However, in this study, the sample size is too small for definite conclusion regarding the effect of the age of the school buildings studied.

From the monitored noise levels, it can be appreciated that noise pollution does exist in all the schools studied thus making the school environments not suitable for the teaching-learning process, and is likely to pertain in several other schools in Ghana. According to [2], a safe and healthy school environment is crucial for students' health as well as for effective and fruitful education. Moreover, [40] revealed that background noise level interferes with speech and results 
in significant drop in children's performance, particularly in learning to read. Addressing the exposure to such noise levels in school the environment should be considered as a priority since it could result in significant impact on the performance of pupils. Appropriate measures should be employed to guide the design and development of new school buildings and the improvement of existing stock of learning spaces in basic schools in Ghana. health should be raised to prevent the congestion of schools with activities of potentially high noise sources which are not acoustically suitable [41].

A study by [15] to compare performance of children in primary school classrooms that had been acoustically treated, with children in untreated classrooms, revealed that children in acoustically treated rooms, performed better in word intelligibility tests. Furthermore, [41] reported that, proper tree-shrub-grass combination could attenuate noise up to about $12 \mathrm{~dB}$. Sound attenuation options including sound proofing, envelope insulation, sound absorption techniques, use of noise barriers, setbacks and greenbelts should be exploited and adopted at the landuse planning and design stages of schools to locate sensitive learning spaces far from sources of noise near or within schools. Beyond sound attenuation measures, the respective metropolitan and district authorities should enact legal frameworks to regulate speed limits of vehicles within or near educational environments as part of traffic laws to control noise pollution [42] [43] [44].

This study was presented with a typical challenge where noise levels were measured with the presence of both teachers and students in their classes. Further studies measuring noise level in unoccupied classrooms during break times should be carried out and compared with the recommended levels. Moreover, the effects of varied classroom dimensions, number of students in a class and floor level on a multi-storey block of a given classroom on indoor noise levels should be investigated in future studies.

\section{Conclusions}

The study was informed by the fact that a number of basic schools in Ghana are located in heavily populated residential and commercial zones which expose them to environmental noise. The objective of the study was to assess prevailing noise levels in and around learning spaces in community basic schools in Kumasi, a city in Ghana. The study revealed that the basic schools studied had noisy learning environments exceeding the World Health Organisation permissible ambient noise level limits and not conducive for proper child development. Mean outdoor and indoor noise levels for schools in the commercial zones and near highway exceed the permissible limits by $30 \%-40 \%$ and $90 \%-107 \%$ respectively during the cause of the day. On the other hand, the school sited in educational environments and with adequate setback from the highway has noise levels ranging from $1.2 \%$ below to $3.7 \%$ above the permissible limits for outdoor and $64 \%$ and $105 \%$ for indoor.

It is expected that when the above recommendations are implemented in the 
development of new basic schools and management of existing ones, learning spaces in schools will be free from excessive noise that is above the prescribed limits for educational institutions, thus promoting effective teaching and learning, and enhance the performance of pupils

The outcome of the study is expected to engender the design of environmental noise resilient buildings for basic schools in Ghana. This will go a long way to enhance the character of the learning environment of basic schools, facilitate teaching and learning, and improve pupils' academic performance.

\section{Conflicts of Interest}

The authors declare no conflicts of interest regarding the publication of this paper.

\section{References}

[1] Shield, B. and Dockrell, J. (2003) The Effects of Noise on Children at School: A Review. Building Acoustics, 10, 97-106. https://doi.org/10.1260/135101003768965960

[2] Alsubaie, A.S.R. (2014) Indoor Noise Pollution in Elementary Schools of Eastern Province, Saudi Arabia. Journal of Research in Environmental Science and Toxicology, 3, 25-29.

[3] WHO (1987) The Ottawa Charter for Health Promotion. Health Promotion International.

[4] Bess, F.H., Gustafson, S.J. and Hornsby, B.W.Y. (2014) How Hard Can It Be to Listen? Fatigue in Students with Hearing Loss. Journal of Educational, Pediatric \& (Re) Habilitative Audiology, 20, 34-47.

[5] Kamal, M., El-Rahman, R.A. and Tawfiq, S. (2010) Evaluation of Noise Levels affecting Schools in Cairo, Egypt. Proceedings of ISMA 2010, Leuven, 20-22 September 2010, 1811-1820.

[6] WHO (2004) The Physical School Environment, an Essential Component of a Health-Promoting School (WHO/PHE and WHO/NPH).

[7] Zulkepli, H.I. and Hazel, K.R. (2000) Noise Pollution at School Environment Located in Residential Area. Journal of Civil Engineering, 12, 47-62.

[8] Silva, L.T. and Mendes, J.F.G. (2012) City Noise-Air: An Environmental Quality Index for Cities. Sustainable Cities and Society, 4, 1-11. https://doi.org/10.1016/j.scs.2012.03.001

[9] Botchway, E.A., Amos-Abanyie, S. and Kwofie, T.E. (2014) Evaluation of Sound Attenuation Effect in Recording Studios: Case of Angel FM Station in Kumasi, Ghana. Journal of Building Performance, 5, 74-83. http://libdoc.who.int/hq/1990/WHO EHE RUD 90.2.pdf

[10] Bulunuz, N., Bulunuz, M., Orbak, A.Y., Mulu, N. and Tavşanli, O.M. (2017) An Evaluation of Primary School Students' Views about Noise Levels in School. International Electronic Journal of Elementary Education, 9, 725-740.

[11] Gilavand, A. and Jamshidnezhad, A. (2016) The Effect of Noise in Educational Institutions on Learning and Academic Achievement of Elementary Students in Ahvaz, Southwest of Iran. International Journal of Pediatrics, 4, 1453-1463.

[12] WHO (2014) What Is a Health Promoting School? School and Youth Health. http://www.who.int/school youth health/gshi/hps/en 
[13] Goswami, B., Hassan, Y. and Sarma, A.J.D. (2018) The Effects of Noise on Students at School: A Review. International Journal of Latest Engineering and Management Research, 3, 43-45.

[14] Shield, B.M. and Dockrell, J.E. (2002) The Effects of Environmental Noise on Child Academic Attainments. Proceedings of the Institute of Acoustics, 24.

[15] MacKenzie, D. (2000) Noise Sources and Levels in UK Schools. Proceedings International Symposium on Noise Control and Acoustics for Educational Buildings, Istanbul, Vol. 5, 97-106.

[16] Occupational Safety and Health Administration [OSHA] (2014) Technical Manual. https://www.osha.gov/dts/osta/otm/otm extended toc.html

[17] Squires, E., Pakulski, L.A., Diehm, E. and Glassman, J. (2016) Measuring Classroom Acoustics.

[18] Pakulski, L.A., Glassman, J., Anderson, K. and Squires, E. (2016) Noise Pollution (Noise-Scape) among School Children. Journal of Educational, Pediatric \& (Re) Habilitative Audiology, 22, 1-9.

[19] Bar, M.A. and Ratzon, N.Z. (2016) Enhancing Occupational Therapy Students' Knowledge, Competence, Awareness, and Interest in Accessibility. Hong Kong Journal of Occupational Therapy, 27, 18-25. https://doi.org/10.1016/j.hkjot.2016.04.001

[20] Fryer, L.K. (2016) Modelling the Links between Students' Interest in a Domain, the Tasks They Experience and Their Interest in a Course: Isn't Interest What University Is All About. University of Sydney, Sydney. https://doi.org/10.1016/j.lindif.2016.08.011

[21] Buchari and Matondang, N. (2017) The Impact of Noise Level on Students' Learning Performance at State Elementary School in Medan. AIP Conference Proceedings, 1855, Article ID: 040002. https://doi.org/10.1063/1.4985498

[22] Waye, K.P., Fredriksson, S., Hussain-Alkhateeb, L., Gustafsson, J. and van Kamp, I. (2019) Preschool Teachers' Perspective on How High Noise Levels at Preschool Affect Children's Behavior. PLoS ONE, 14, e0214464. https://doi.org/10.1371/journal.pone.0214464

[23] WHO (1999) Guidelines for Community Noise. World Health Organization, Geneva.

[24] Amoako, C. and Korboe, D. (2011) Historical Development, Population Growth and Present Structure of Kumasi. In: Adarkwa, K.K., Ed., The Future of the Tree: Towards Growth and Development of Kumasi, University Printing Press (UPK), Kumasi, 35-55.

[25] Mensa-Bonsu, I.F. and Owusu-Ansah, K. (2011) State of the Environment in Kumasi. In: Adarkwa, K., Ed., The Future of the Tree: Towards Growth and Development of Kumasi, University Printing Press (UPK), 174-194.

[26] Kumasi Metropolitan Assembly (2015).

[27] Murthy, V.K. and Khanal, S.N. (2007) Assessment of Traffic Noise Pollution in Banepa, a Semi Urban Town of Nepal. Kathmandu University, Journal of Science, Engineering and Technology, 1, 1-9.

[28] Hygge, S. (1993) Classroom Experiments on the Effects of Aircraft, Traffic, Train, and Verbal Noise on Long-Term Recall and Recognition in Children Aged 12-14 Years. Proceedings of the 6 th International Congress on Noise as a Public Health Problem, Vol. 2, 531-534.

[29] Szokolay, S.V. (2004) Introduction to Architectural Science: The Basis of Sustaina- 
ble Design. Architectural Press, Oxford.

[30] Sanz, S. Garcia, A. and Garcia, A. (1993) Road Traffic Noise around Schools: A Risk for Pupils Performance? International Archives of Occupational and Environmental Health, 65, 205-207. https://doi.org/10.1007/BF00381157

[31] Romero, J. and Lliso, D. (1995) Perception and Acoustic Conditions in Secondary Spanish Schools. Proceedings of the 15th International Congress on Acoustics, Trondheim, 26-30 June 1995, 271-274.

[32] Debnath, D., Nath, S.K. and Barthakur, N.K. (2012) Environmental Noise Pollution in Educational Institutes of Nagaon Town, Assam, India. Global Journal of Science Frontier Research Environment \& Earth Sciences, 12, 1-6.

[33] Koranteng, C. (2011) The Thermal Performance of an Educational Office Building in Ghana. Journal of Applied Science and Research, 3, 222-232.

[34] Gyamfi, C.K.R., Isaac Amankwaa, I., Sekyere, F.O. and Boateng, D. (2016) Noise Exposure and Hearing Capabilities of Quarry Workers in Ghana: A Cross-Sectional Study. Journal of Environmental and Public Health, 2016, Article ID: 7054276. https://doi.org/10.1155/2016/7054276

[35] Omari, S., De-Veer, A. and Amfo-Out, R. (2013) The Silent Killer: An Assessment of Level of Industrial Noise and Associated Health Effects on Workers. International Journal of Basic and Applied Sciences, 2, 165-169. https://doi.org/10.14419/ijbas.v2i2.657

[36] Abankwa, E.O. (2014) Study of Noise Levels in the City of Kumasi. An Unpublished Degree of Master of Science in Mechanical Engineering Thesis, The Kwame Nkrumah University of Science and Technology, Kumasi.

[37] Picard, M. and Bradley, J. (2001) Revisiting Speech Interference in Classrooms. Audiology, 40, 221-224. https://doi.org/10.3109/00206090109073117

[38] Shield, B.M. and Dockrell, J.E. (2003) External and Internal Noise Surveys of London Primary Schools. Journal of the Acoustical Society of America, 115, 730-738.

[39] Ozer, S., Yilmaz, H., Yesil, M. and Yesil, P. (2007) Evaluation of Noise Pollution Caused by Vehicles in the City of Tokat, Turkey. Scientific Research and Essay, 4, 1205-1212.

[40] Hetu, R., Truchon-Gagnon, C. and Bilodeau, S.A. (1990) Problems of Noise in School Settings: A Review of Literature and the Results of an Exploratory Study. Journal of Speech-Language Pathology and Audiology, 14, 31-38.

[41] Shahid, M.A.K. and Bashir, H. (2013) Psychological and Physiological Effects of Noise Pollution on the Residents of Major Cities of Punjab (Pakistan). Peak Journal of Physical and Environmental Science Research, 1, 41-50. http://www.peakjournals.org/sub-journalsPJPESR.html

[42] Das, A.B. (2006) Noise Pollution: Its Environmental Implication and Evaluation. E-Planet, 4, 26-28.

[43] Datta, J.K., Sadhu, S., Gupta, S., Saha, R., Mondal, N.K. and Mukhopadhyay, B. (2006) Assessment of Noise Level in Burdwan Town, West Bengal. Journal of Environmental Biology, 27, 609-612.

[44] Garg, S., Garg, R. and Garg, R. (2007) Environmental Science and Environmental Studies. Khanna Publishers, New Delhi. 